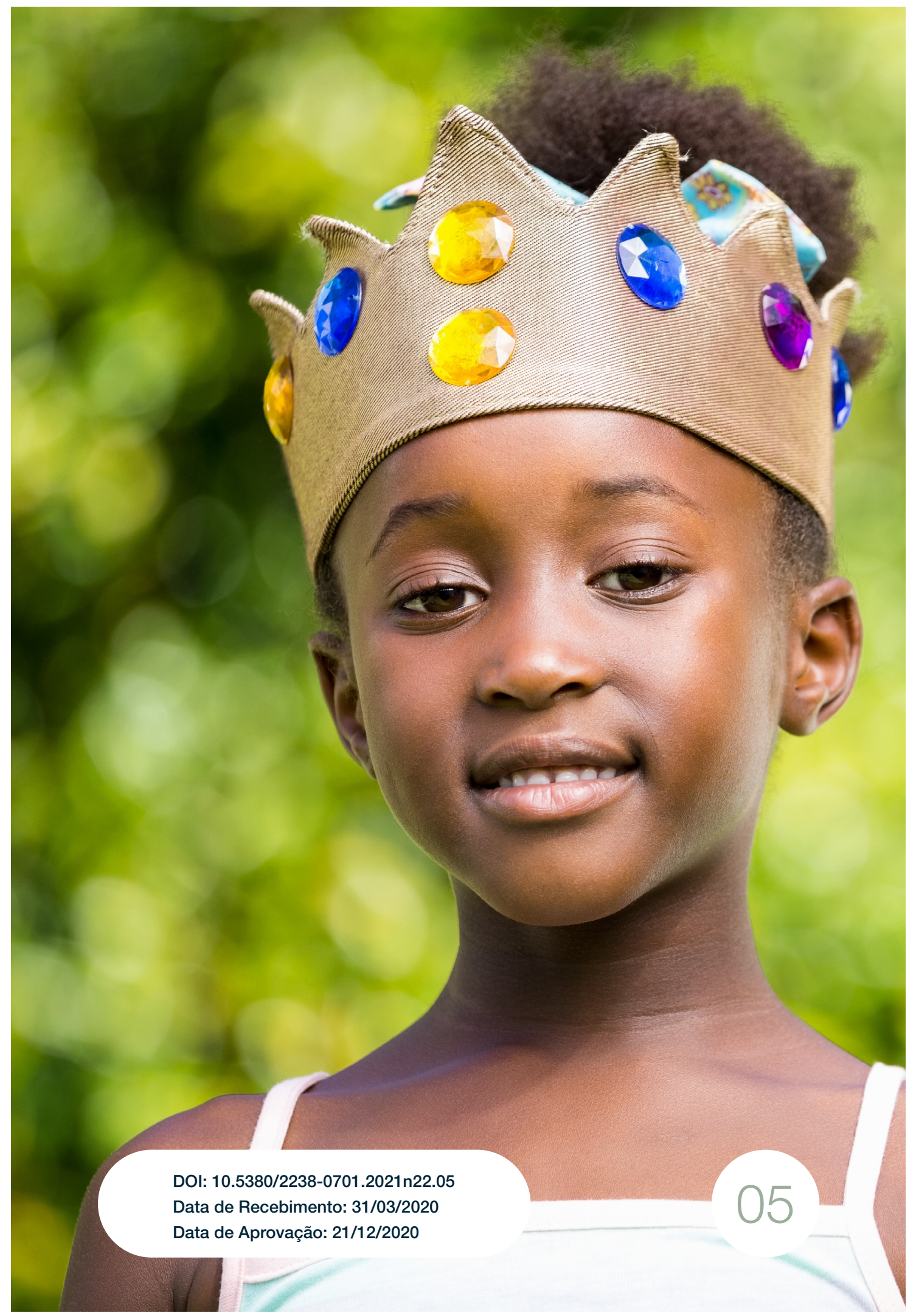


Modos de Ser Menina: das princesas clássicas nas narrativas audiovisuais ao empoderamento feminino na produção televisiva nacional 


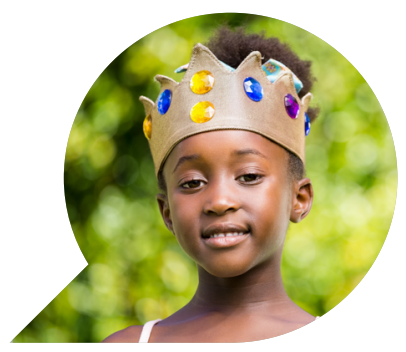

\title{
Modos de Ser Menina: das princesas clássicas nas narrativas audiovisuais ao empoderamento feminino na produção televisiva nacional
}

\author{
Modes of Being a Girl: from classic princesses in \\ audiovisual narratives to female empowerment in \\ national television production
}

Modos de ser niña: de las clásicas princesas en las narrativas audiovisuales al empoderamiento femenino en la producción televisiva nacional

BEATRIZ BECKER ${ }^{1}$

BEATRIZ LOBO SANTOS²

Resumo: A televisão sofre intensas reconfigurações na atualidade que afetam de maneira expressiva a produção, a circulação e o consumo de conteúdos direcionadas ao público infantojuvenil. Buscando articular relações entre televisão, feminismo e infância, refletimos neste artigo sobre representações das princesas nas

\footnotetext{
1 Professora do Programa de Pós-Graduação em Comunicação e Cultura da Escola de Comunicação da Universidade Federal do Rio de Janeiro (PPGCOM-ECO/UFRJ), líder do Grupo de Pesquisa Mídia, Jornalismo Audiovisual e Educação (MJAE) e bolsista de produtividade do CNPq.

2 Mestre em Comunicação pelo Programa de Pós-Graduação em Comunicação e Cultura da Universidade Federal do Rio de Janeiro (PPGCOM-UFRJ), membro do Grupo de Pesquisa Mídia, Jornalismo Audiovisual e Educação (MJAE).
} 
narrativas audiovisuais, destacando os programas televisivos nacionais. A partir de um mapeamento das maneiras como são construídas essas personagens em contextos históricos e culturais distintos e da Análise Televisual da animação brasileira Escola de Princesinhas, identificamos que os atributos conferidos aos modos de ser menina em conteúdos infantojuvenis que tomam as princesas como protagonistas resultam tanto da homogeneização da cultural global quanto do despontar de resistências e mudanças sociais no país.

Palavras-chave: televisão; programação infantil; princesa, feminismo

Abstract: Television is currently undergoing dramatic changes that significantly affect the production, distribution and consumption of contents designed for children and young people. Seeking to articulate the relationships between television, feminism and childhood, this paper discusses the representation of princesses in the audiovisual narratives, especially in Brazilian television programmes. Through the mapping of the ways in which these characters are built in different historical and cultural backgrounds and the Television Analysis of the Brazilian animation "Escola de Princesinhas", this paper identifies that the attributes associated with "being a girl" in youth television programmes that turn the princesses into protagonists result from both the global cultural homogenization and the emergence of resistance and social changes in Brazil.

Keywords: Television; Youth television programmes; Princess; Feminism

Resumen: Actualmente la televisión viene sufriendo drásticas reconfiguraciones que afetam de forma expressiva la producción, circulación y el consumo de contenidos para la audiencia infantil y juvenil. Buscando articular las relaciones entre televisión, feminismo y infância, discutimos neste artigo las representaciones de las princesas en narrativas audiovisuales, dando destaque a los programas televisivos brasileños. Partiendo de uno mapeamento de las formas como son construidas las personages en contextos históricos y culturales distintos, y haciendo uso de la Analise Televisual de la animación "Escola de Princesinhas", identificamos que los atributos dados 
a los modos de ser niña en los contenidos de princesas resultan tanto de la homogeneización de la cultura global como de lo levante de resistencias y mudanças sociales en Brasil.

Palabras-clave: televisión; programación infantil; princesa; feminismo

\section{Introdução}

A televisão sofre intensas reconfigurações na atualidade que afetam de maneira expressiva os modos de produção, circulação e consumo de conteúdos e formatos audiovisuais. A tevê aberta mantém a sua centralidade no ambiente convergente, potencializando a distribuição e a comercialização de conteúdos em plataformas de vídeo on demand (VOD), via streaming, aplicativos e redes sociais. Assim, ainda reúne índices de audiência muito expressivos e concentra mais de $50 \%$ do volume de investimentos por meio, cerca de 75 bilhões de reais ${ }^{3}$. Contudo, ao observarmos a composição da grade de programação das emissoras comerciais, identificamos que somente o SBT e a Band veiculam programas infantis em rede nacional. Mas conteúdos direcionados ao público infantojuvenil são acompanhados na TV por assinatura por expressivas e crescentes audiências em canais próprios das emissoras de televisão aberta e estrangeiros, em nichos segmentados diversos na internet, bem como via aplicativos. O smartphone é o dispositivo mais usado por crianças e jovens, e as animações são um dos cinco produtos em vídeo mais consumidos. Segundo o relatório Mídia Dados 2019, o Brasil já ocupa o quarto lugar no ranking dos países com maior número de usuários da internet, $70 \%$ da população estimada em mais de 210 milhões de pessoas ${ }^{4}$.

No ambiente convergente, a análise dos programas televisivos se torna mais complexa, o que impõe ampliar o olhar para suas enunciações sem restringir o entendimento desses processos comunicativos a estratégias de controle social ou a instrumentos de promoção de valores retrógrados, hierarquizações e estereótipos centrados nas

3 Estes dados se referem ao volume acumulado de investimentos em 2018, em acordo com o relatório Mídia Dados 2019. Disponível em: https://www.gm.org.br/midia-dados-2019; Acesso em: 23 mar. 2019.

4 Cf: http://159.89.80.182/midia-dados-sp/public/Midia\%20Dados\%202019.pdf. Acesso em 23 mar.2020. 
culturas dominantes e nos interesses do capital. As lógicas de produção também operam de acordo com as demandas dos receptores, são construídas culturalmente e não se reduzem à transmissão unilateral de mensagens, pois as pesquisas em Comunicação já apontam que o público não responde a automatismos comportamentais enganado pelas mensagens prejudiciais dos programas televisivos e se constitui como uma audiência ativa (FUENZALIDA, 2016).

Tomando a TV como dispositivo pedagógico, como propõe Fischer (2002), sugerimos que a televisão "ensina" modos de ser e de estar na vida cultural e social e exerce papel relevante na constituição de sujeitos e de subjetividades, porém, há múltiplos jogos de produção de sentidos que não resultam, previamente, das significações prescritas pelos discursos da mídia e não têm um sentido fixo. Tanto os programas educativos quanto os de entretenimento educam e colaboram para um modo de ver e experimentar o mundo, "de construir ou desestabilizar vínculos sociais, de estabelecer ou diluir fronteiras, de potencializar e/ou inibir a aproximação entre pessoas e grupos sociais" (SAMPAIO; CAVALCANTI, 2012, p. 333). Considerando a infância como uma construção social e a criança como produtora de saberes capaz de atribuir sentidos aos programas e personagens, por meio da atitude interpretativa e de seus agenciamentos, Fenandes e Oswald (2005) vislumbram os desenhos animados como uma mediação de encontro de alteridades e de reconhecimento social. Nesse sentido, as animações podem ser empregadas como ferramentas para educar e estimular a capacidade imaginativa e o autoconhecimento das crianças (PRADO; MUNGIOLI, 2016). No ambiente convergente, elas tecem novas experiências e formas de perceber o mundo e a si próprias, se apropriam de tecnologias digitais, fazem seleções de materialidades visuais, e conexões com outras crianças (FUENZALIDA, 2016). Além disso, as relações que se estabelecem entre produção e recepção despertam a atenção de pesquisadores por impactarem as narrativas sobre a infância contemporânea (TOMAZ, 2017) e os modos de ser menina, pois os desenhos animados também são formas de construção cultural do feminino e do masculino (FARIA, 2006).

O ano de 2020, em que a televisão brasileira completa 70 anos, marca também, curiosamente, o lançamento da versão Disney para a história da Gata Borralheira nos anos 1950, injustiçada pela falta de sororidade do universo feminino e escolhida pelo príncipe encantado 
para ser feliz para sempre. Nas últimas décadas, porém, Cinderela tem se transformado em uma anti-heroína da revolução feminina, por meio de lutas e discursos de movimentos sociais a favor do empoderamento feminino nos contos de fada e na vida social ${ }^{5}$. No mundo do castelo britânico, o desencanto de Lady Di com o príncipe Charles e o rompimento dos laços matrimoniais seguido de morte trágica da plebeia que havia se transformado em princesa, bem como a desistência de um pertencimento formal à realeza da Duquesa Meghan Markle, desestabilizaram seculares tradições. Nos contos de fadas midiáticos, os sonhos das meninas que tinham como principal projeto futuro o romance com um príncipe foram se transformando, elas se tornaram mais independentes e passaram a cultivar o amor-próprio. As mudanças das representações do feminino nas narrativas audiovisuais que tomam as princesas como protagonistas não deixaram de atrair audiências diversas e gerar rendimentos bilionários para poderosos grupos de entretenimento. No entanto, mais do que identificar as sofisticadas estratégias de comercialização dessas histórias distribuídas em diferentes mídias e o consequente consumo em grande escala de brinquedos, roupas, maquiagens e outros artefatos, refletimos neste trabalho sobre as construções da figura de princesa em regimes históricos e culturais específicos. A partir de um mapeamento dos atributos conferidos a essa personagem na produção audiovisual e, mais especificamente, nos programas televisivos nacionais, bem como da Análise Televisual (BECKER, 2012, 2016) da animação brasileira Escola de Princesinhas, assumimos que os sentidos das princesas em desenhos e seriados animados resultam tanto da mediação da mídia hegemônica quanto de disputas discursivas e mudanças sociais no país. Assim, buscamos contribuir para o entendimento das complexas relações entre televisão, feminismo e infância.

\section{Uma História de Princesas}

Hains e Brunnel (2015) chamam de "princess cultures" os modos de meninas de diferentes partes do planeta se relacionarem com essas personagens que criam um ideal de feminino dependente e frágil. Para

5 Disponível em: https://vogue.globo.com/semidade/Viva-a-Coroa/noticia/2020/03/cinderela-70-anos.html. Acesso em 18 mar. 2020. 
Basso (2000, p.10), as "representações de figuras femininas se oferecem como modelo identitário e são consumidas como mitos", pois pesquisadoras feministas ressaltam que as representações das princesas reforçam padrões estéticos e comportamentais que afetam o desenvolvimento de meninas enquanto sujeitos. Entretanto, os atributos conferidos a essas personagens são permeados por continuidades e rupturas, como evidenciamos nesse mapeamento das construções da figura da princesa na produção audiovisual. Como marco axial, elegemos o primeiro longa-metragem animado sobre princesas, criado em 1937 nos estúdios Disney: Branca de Neve e os sete anões. A protagonista caracteriza a configuração simbólica do gênero feminino à espera de seu salvador (BREDER, 2013, p. 47). O filme Cinderela foi lançado em 1950, quando o ideal de virtude relacionado à passividade e obediência da mulher ainda era valorizado. Esse comportamento feminino, caracterizado pela dependência da dominação masculina e a necessidade patológica de um "amor" transfigurado em devoção ao homem, foi nomeado de "Complexo de Cinderela" por Colette Dowling, em 1981. O lançamento, nove anos depois, de A Bela Adormecida completou o trio de princesas clássicas dos estúdios Disney, conformando a ideia de uma feminilidade submissa e pacata em uma sociedade antropocêntrica e patriarcal (BOURDIEU, 1998). A emergência da segunda onda do feminismo nos anos 1960 impôs releituras das narrativas principescas clássicas, e foram produzidos contos de fadas adaptados para o cinema e para a televisão com ingredientes de humor e sarcasmo ${ }^{6}$.

Na passagem da década de 1970 para os anos 1980, o surgimento de princesas guerreiras, heroínas e rebeldes, como a Princesa Leia dos filmes Star Wars e She-Ra, a princesa do poder, simbolizam a vontade de se aventurar e a busca pela igualdade de direitos, e introduzem a ideia de um real protagonismo das princesas e do gênero feminino (LEBLANC, 2017). Ariel, Bela, Jasmine, Pocahontas e Mulan são princesas lançadas pelos estúdios Disney na década seguinte, que já não esperam pela salvação do príncipe encantado e têm autonomia para escolher seus destinos e cuidar de si mesmas (HEATWOLE, 2016). Nos anos 1990, as personagens principescas apresentam personalidades

6 Exemplo é Fractured Fairy Tales, traduzido no Brasil com o nome Contos de Fadas Furados. Este desenho animado foi exibido durante a animação As aventuras de Alceu e Dentinho, na Rede Globo no final dos anos 1990 e, posteriormente, no Cartoon Network. 
fortes, enfrentam regras sociais e questionam o status quo (BREDER, 2016), como a altiva princesa ameríndia Pocahontas. Em 1998, os estúdios Disney lançam Mulan, personagem que não está interessada em casamento e questiona a sua própria identidade. Ela precisa assumir a figura masculina para ser guerreira, porém, encontra um novo caminho, rompe as amarras da cultura patriarcal e passa a ser respeitada como mulher (GALVÃO, 1998).

Histórias originais de princesas ou sequências de reconhecidos clássicos são criadas, distribuídas em VHS, DVDs e veiculadas em canais de televisão a partir dos anos 2000. A inserção pela DreamWorks da princesa Fiona no filme Shrek foge dos padrões de beleza dos corpos femininos das personagens principescas e marca uma reviravolta nos estereótipos de princesa. No século XXI, muitas readaptações animadas em que as princesas são protagonistas incrementam o mercado de produção transmídia e passam a ser consumidas também via streaming e por VOD, especialmente, os live action. Um exemplo é o filme Encantada, lançado em 2007, uma espécie de releitura dos contos de fada que evidencia como estas narrativas transformam os modos de ver a realidade social. Porém, a animação que causou maior impacto nesse período foi $A$ Princesa e o Sapo, protagonizada pela princesa Tiana. "Pela primeira vez na história da animação Disney, a mais bela de todas é negra", escreveu Brooks Barnes para o New York Times ${ }^{7}$. A personagem representa lutas, resistências e conquistas de representatividades sociais as mais diversas na mídia hegemônica. Ela trabalha, como muitas mulheres, e o fio condutor da história é a sua vontade de empreender. Em 2010, o Cartoon Network promove a desmistificação em torno de temas como corpo, gênero e heteronormatividade nas dez temporadas da série $A$ hora da aventura. A ramificação de televisão aberta da Disney, a emissora americana ABC, lança Once upon a time (Era uma Vez), seriado que destaca a importância dos relacionamentos entre mães e filhas para a formação e o posicionamento social da menina no contexto pós-feminista (HEATWOLE, 2016). Em 2013, Frozen se constitui em um fenômeno de bilheteria da franquia Disney Princess, colocando em questão a crença no príncipe encantado e privilegiando o amor fraternal e a família. Em 2016, uma nova animação sobre

7 Disponível em: https://www.tesd.net/cms/lib/PA01001259/Centricity/Domain/295/Does\%20Tiana\%20Disneys\%20First\%20Black\%20Princess\%20Conquer\%20Stereotypes.pdf. Acesso em: 10 de nov. 2019. 
princesas é lançada pela Disney: Moana: um mar de aventuras. Diferentemente das princesas rebeldes que representam mulheres que saem em busca de seus sonhos motivadas por um homem, a personagem revela a importância do amor-próprio e à comunidade (BREDER, 2016). Wi-fi Ralph (2018) é o primeiro filme deste poderoso grupo de entretenimento que reúne todas as princesas em uma única cena, destacando a importância da interação entre as meninas e respondendo a ações políticas de empatia e cooperação entre mulheres no Brasil e em outros países (LEAL, 2018). Os remakes em live action de histórias principescas produzidos na atualidade também apontam algumas alterações nos enredos dos contos de fada tradicionais, revisando enquadramentos do feminino no passado em sincronia com aspirações de movimentos feministas. Em seguida, focalizamos as maneiras como as princesas são construídas e inseridas na produção televisiva nacional.

\section{Mapeando a Produção Audiovisual Brasileira}

As animações sempre fizeram parte importante da programação da tevê, desde as primeiras décadas da sua implantação no Brasil, mas a produção nacional de desenhos animados era muito restrita. Na década de 1950, os primeiros programas direcionados ao público infantojuvenil eram adaptações de produções do rádio ou de textos teatrais e literários. As narrativas principescas correspondiam às adaptações de livros muito conhecidos, como o programa Fábulas Animadas, dirigido por Tatiana Belinsky e exibido na TV Tupi (FIEL, 2019). Nesse período havia também programas de variedades, cujos nomes eram acompanhados das marcas dos patrocinadores, e foram lançados programas com formatos educativos e de entretenimento e as primeiras experiências de telenovelas destinadas ao público infantil (Idem).

A chegada do vídeo-tape na década de 1960 transformou os modos de produzir e consumir TV, mas a maioria dos programas infantis era comandada por adultos, e quase todos os desenhos animados veiculados nas emissoras de TV aberta eram estrangeiros $(\mathrm{HOLZBACH}$, 2018). Nos anos 1970, foi lançado o primeiro programa jornalístico dirigido ao público infantil, o Globinho e a atração Vila Sésamo, formada por quadros curtos e adaptada da produção norte-americana, 
que alcançou grande sucesso. Quando as cores chegaram à telinha, a programação infantil ganhou ainda mais destaque, sobretudo, com o sucesso da quarta versão do Sítio do Picapau Amarelo, integrando as aventuras dos conhecidos protagonistas nacionais a contos clássicos da literatura (FIEL, 2019). Entretanto, a maior parte dos desenhos animados continuava a ser comprada de produtoras estrangeiras. As primeiras experiências nacionais de animação emergiram em campanhas publicitárias (HOLZBACH, 2018).

Nos anos 1980, são exploradas novas linguagens, e os programas de auditório se fortaleceram, como a exibição de Bozo, no SBT, uma das franquias de maior sucesso no mundo caracterizada por uma estética circense. O Balão Mágico foi lançado pela Globo como ofensiva à atração do palhaço com uma grande novidade: o comando do programa passou a ser centrado na figura de uma criança. O sucesso deste programa, que também veiculava animações, só foi superado pelo programa da apresentadora Xuxa Meneghel, lançado na Rede Manchete e exibido, posteriormente, na Rede Globo. O cenário reproduzia um grande parque, no qual as crianças pudessem se divertir. Foram lançadas também telenovelas para o público infantojuvenil (FIEL, 2019). O segundo filme do cartunista Maurício de Souza, A princesa e o robô, lançado em 1983, e outras histórias tornaram a forte personagem da menina Mônica um símbolo da luta pelo empoderamento feminino no país. Seis anos depois, A princesa Xuxa e os Trapalhões alcançou grande sucesso. A história apresentada, da princesa Xaron, não correspondia aos moldes clássicos da protagonista frágil e se aproximava da princesa guerreira She-Ra ${ }^{8}$. Contudo, nos anos 1980, a criança se tornou alvo de campanhas publicitárias, incentivadas a um consumo desenfreado de produtos vinculados às produções televisivas. A popularização do videocassete contribuiu tanto para a criação de conteúdos e estéticas diversas quanto para o incremento deste mercado.

Na década de 1990, com exceção da TV Cultura, que apresentava programas lúdicos e criativos, indicando que na TV também poderiam existir obras audiovisuais de qualidade reconhecida pelo público e pela crítica, a lógica dos canais comerciais era entreter e lucrar. As emissoras comerciais de TV aberta reduziram o tempo da programação

8 Xuxa ainda atuou como princesa em Xuxa e os Duendes (2001), em Xuxa e os Duendes 2 (2002) e, acompanhada de um grupo de princesas, em Xuxa e o Mistério de Feiurinha (2008), uma adaptação do livro homônimo de Pedro Bandeira. 
para crianças, sobretudo, após a aprovação da Resolução 163 do CONANDA $^{9}$, que dispõe sobre a abusividade do direcionamento de publicidade e de comunicação mercadológica à criança e ao adolescente (FIEL, 2019). A implantação da televisão por assinatura abriu novos espaços para a programação infantil com a criação de inúmeros canais de entretenimento. Programas de estúdio substituíram os de auditório, apresentados por crianças ou adultos. Foram criados marcos legais de regulamentação do mercado de TV paga que também abriram espaço para os produtores locais (HOLZBACH, 2018; FIEL, 2019). A TV Brasil, criada em 2007, pertencente à EBC, continuou a investir na programação infantil. Porém, a implantação do sinal digital no Brasil nos anos 2000 provocou mudanças na grade das emissoras de TV aberta, e programas direcionados às crianças foram extintos (idem).

No século XXI, entretanto, a expansão da produção de conteúdo televisivo para múltiplas plataformas e do consumo via streaming e por diferentes dispositivos tem acentuado a construção de novos formatos. A cultura e as tecnologias digitais favorecem os grandes conglomerados de mídia, mas também colaboram para a ampliar a produção nacional de animações, sobretudo na TV por assinatura. Conteúdos direcionadas às crianças em ambientes como o YouTube e a Netflix crescem em proporções geométricas, atraem milhões de visualizações, operam com sofisticadas estratégias de distribuição transmidiáticas e passam a ser concebidos como episódios em narrativas seriadas ( $\mathrm{HOLZBACH;}$ DORNELLES, 2020). Histórias de princesa na produção televisiva nacional ganham destaque, e exemplos são a animação SOS Fada Manu, criada pela produtora Boutique em parceria com o estúdio de animação LightStar Studios e exibida no Gloobinho e na TV Brasil, e Escola de princesinhas, lançada pela produtora Vídeo Brinquedo e disponível no canal desta produtora no YouTube ${ }^{10}$, reunindo representações diversas e irreverentes das protagonistas que estudam juntas e aprendem lições de cidadania e de amizade. Buscando perceber como o audiovisual atua como tecnologia de gênero (LAURETIS, 1984) e observar

\footnotetext{
9 Disponível em https://www.direitosdacrianca.gov.br/@@search?SearchableText=resolu\%C3\%A7\%C3\%A30+163. Acesso em: 24 mar. 2020.

10 Os primeiros episódios desta animação começaram a ser produzidos em 2007 em DVD e, dois anos depois, foram exibidos na televisão na grade da TV Rá-Tim-Bum. Em 2014, Escola de Princesinhas foi integrada à programação da Rede TV e veiculada no programa infantil TV Kids. Hoje, os episódios compõem a lista de streaming infantil da Prime Vídeo e estão disponíveis no YouTube em: https://www.youtube.com/user/videobrinquedooficia. Acesso em 26 mar. 2020.
} 
como os ideais de feminino são construídos em Escola de Princesinhas, apresentamos em seguida uma síntese da Análise Televisual das cinco temporadas desta animação, formadas por três episódios cada. Este percurso metodológico é formado por três etapas: a Descrição do objeto de estudo, a Análise Televisual (AT) propriamente dita, composta por um estudo quantitativo e qualitativo ${ }^{11}$ e a Interpretação dos Resultados.

\section{Análise Televisual da Escola de Princesinhas}

Escola de Princesinhas é uma das animações mais recentes e de maior sucesso da Vídeo Brinquedos (Figura 1), uma reconhecida produtora de conteúdo no mercado nacional sediada em São Paulo que investe em adaptações de animações de sucesso desde 1994 e, com orçamento restrito, já lançou vários títulos com referências diretas às produções da Disney e da DreamWorks. Essas animações integram os mockbusters, produtos audiovisuais criados para o aproveitamento da publicidade de versões originais já lançadas ou em pré-lançamento (PINO, 2019). A personalidade, o comportamento e os nomes das princesas clássicas foram alterados. Cinderela virou Cindy, Branca de Neve passou a ser chamada de Bianca, Mulan se tornou Hime, Jade assumiu o nome de Zade ${ }^{12}$, e Tiana inspirou a figura de Iriá, uma princesa de raízes africanas cujas características são a sabedoria e a capacidade de fazer magia.

11 As seis categorias aplicadas no estudo quantitativo são: Estrutura da Narrativa, Temática, Enunciadores, Visualidade, Som e Edição. No estudo qualitativo são aplicados três princípios de enunciação: Fragmentação, Definição de Identidades e Valores e Dramatização (BECKER, 2012; 2016).

12 A aparência de Zade faz referência à princesa Jasmine, da Disney, mas o seu nome é também inspirado em outra personagem, a princesa árabe Sherazade, do conto As mil e uma noites. 
Figura 1 - As princesas da Vídeo Brinquedo

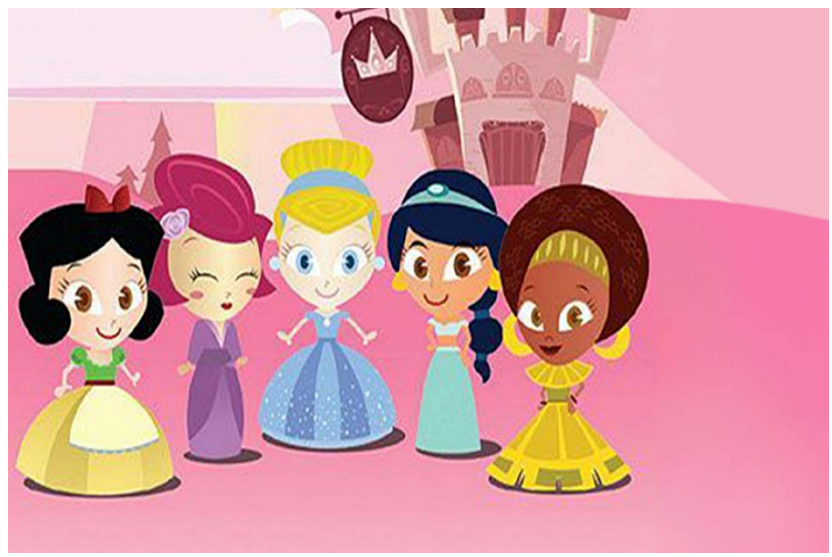

Fonte: Capa de divulgação do seriado ${ }^{13}$

Ao observamos a Estrutura Narrativa da animação seriada no estudo quantitativo da AT, evidenciamos que os arcos dramáticos internos de cada episódio têm cerca de quinze minutos de duração e são quase independentes. Os episódios da animação narram o cotidiano escolar das cinco princesas com personalidades distintas. Elas aprendem lições valiosas para se tornarem heroínas de seus próprios contos de fada, e cada uma colabora de uma maneira diferente para, em conjunto, solucionarem diversos problemas. Cindy é aventureira e a líder do grupo, Bianca é a princesa mais ingênua e afetiva, Zade é a protagonista mais romântica e medrosa do grupo, Hime é atleta e muito valente e Iriá é a melhor aluna e conselheira das amigas. Além das princesas, a figura da madrasta da Branca de Neve foi incorporada à Madame Drástica, a professora responsável pelas meninas. Outros personagens que compõem a trama são a diretora da escola, Senhora Grimm, em alusão ao sobrenome dos autores de boa parte dos contos de fadas; Dango, o anão e zelador do colégio; e Bela, Zéu e Migu, professores de etiqueta e de educação física.

A principal temática de Escola de Princesinhas é a amizade, e tanto a individualidade quanto a cooperação são ressaltadas para o enfrentamento de desafios. A vontade de se aventurar de Cindy leva as meninas a se envolverem em confusão, mas também a ganharem conhecimentos.

13 Disponível em: https://filmow.com/escola-de-princesinhas-t272668/. Acesso em: 0 mar. 2020. 
A ingenuidade de Bianca e seu amor por animais complica a vida das protagonistas e também as protege de diversas situações. A ousadia de Hime nem sempre é compreendida, porém, ajuda as princesas a terem coragem. Iriá é a referência das meninas para qualquer dúvida. E Zade, ainda que tenha muito medo, aprende a superá-lo com e pelas amigas, solucionando muitas dificuldades do grupo.

As vozes e falas das personagens são elementos importantes na pedagogia das narrativas infantis. Em Escola de Princesinhas, as meninas são as principais enunciadoras do texto, movidas pela cumplicidade e pela busca por aventuras. Elas são vaidosas e delicadas, ficam felizes em pensar em príncipes encantados e se divertem em bailes. Entretanto, não são frágeis e pacatas, quebram regras e resolvem seus próprios problemas. Os professores e a diretora da Escola também assumem um papel importante nas enunciações do texto. São eles que devem instruir as meninas a como se comportar. Mas, enquanto as meninas propagam um ideal de independência e protagonismo, os professores tentam enquadrá-las como princesas indefesas. Esses posicionamentos contrastantes abrem diversas possibilidades de interpretações dos sentidos do texto.

A visualidade do seriado é constituída por desenhos muito simples, composta por formas geométricas primárias utilizadas na construção das personagens e dos cenários. As animações interativas são criadas com o software Adobe Flash em 2D. Por isso, o visual de Escola de Princesinhas não tem muita profundidade, é trabalhado apenas com o uso de uma paleta de cores em degradê com pouco uso de luzes e sombras. Os sentimentos de felicidade e medo, bem como a ironia ou cansaço são sempre expressos em um mesmo tipo de expressão facial no rosto das personagens, o que limita a empatia com o espectador. No episódio O Gigante e a Borboleta, por exemplo, quando a Senhora Grimm dá uma terrível notícia, tanto ela quanto todos que a escutam permanecem sorrindo. Além disso, a maneira como as personagens se deslocam em pequenos pulinhos e os saltos nas aulas de educação física evidenciam pouca elaboração da animação de movimentos.

O uso do som na animação é um elemento crucial para a assimilação desse universo ficcional, acentuando as emoções que faltam nos rostos das meninas ou criando momentos de suspense e leveza da trama. As trilhas sonoras modulam os sentimentos das cenas e as 
ações de personagens. Uma abertura musical precede os episódios para introduzir as personagens, seguida da apresentação do título de cada episódio em uma cartela visual enunciada por um narrador. Com acordes e versos repetitivos, a música tema foi criada para ser facilmente reconhecida. Esta forma de sonorização também é utilizada nas situações em que as meninas se encontram próximas do desfecho de suas aventuras ao final de cada episódio. São usados muitos ruídos, como o tilintar de sapatos quando as meninas andam ou o ranger de portas, e efeitos animados para comporem o universo mágico das cinco princesas. A montagem do seriado animado segue a estrutura da narrativa clássica para não ser percebida. Entretanto, a sequência dos quadros não contribui para tornar mais fluidas as ações das personagens, e as limitadas movimentações das protagonistas causam estranhamento. As janelas de transição são muito usadas e de forma lúdica, em círculos que absorvem o quadro e mudam a cena ou em zooms in em determinado objeto.

O estudo qualitativo da AT da Escola de Princesinhas permitiu verificar que a inserção deste seriado no ambiente convergente ocorreu ao longo de sete anos, de maneira fragmentada. Nas transmissões do seriado na televisão aberta, os episódios não foram interrompidos por intervalos comerciais. Entretanto, no canal da Vídeo Brinquedo no YouTube identificamos a monetização dos vídeos na playlist com aglutinações de vídeos da série desde 2018. Nesta plataforma, são encontradas as temporadas fechadas do seriado, com vídeos de quarenta e cinco minutos cada, separados pelas aberturas e encerramentos de cada um dos episódios. Mas o fluxo narrativo dos episódios é interrompido com a inserção de comerciais pelo próprio YouTube. No Prime Vídeo a animação é disponibilizada da mesma forma do que no canal da produtora no YouTube.

A narrativa de Escola de Princesinhas não acentua a dramatização, a elaboração técnica da animação seriada é pouco sofisticada, e as personagens, criadas em 2D, tampouco atraem a interação do espectador. Além disso, ainda que a trilha sonora seja um recurso importante, a sonorização não é suficiente para assegurar uma conexão contínua com as emoções das personagens. Contudo, essa animação introduz na produção televisiva nacional uma abordagem progressista de histórias de princesas, privilegiando a amizade, a colaboração entre essas 
personagens e a atitude proativa das protagonistas, potencializando ensinamentos e formas de ser e estar no mundo. Se por um lado, Escola de Princesinhas acompanha a narrativa de Wi-Fi Ralph, que sugere cumplicidade entre as princesas clássicas ao juntá-las em uma só narrativa, o seriado inova ao privilegiar o elo entre as meninas como forma de superar dificuldades e limitações.

A maioria dos conteúdos audiovisuais direcionados ao público infantojuvenil é baseada no romance e na sexualidade e ancorada no binarismo homem/mulher ou menino/menina, tornando opacos os conflitos e as contradições em relação à questão de gênero (HOLZBACH; DORNELLES, 2020). Entretanto, nem todos esses textos apontam para uma leitura conservadora da realidade. Se o romance é uma escolha recorrente, não é a única opção de futuro das atuais protagonistas dessas histórias, especialmente, das princesas nas animações nacionais (COUTINHO, 2017). Escola de Princesinhas desenha identidades, regionalizando e reinventando valores e sentidos dessas personagens, que contribuem para despertar leituras e enquadramentos do feminino na infância menos presos às amarras do mercado global e para ressaltar a relevância da sororidade (LEAL, 2018), em consonância com campanhas feministas no país, como \#MeuPrimeiroAssédio, \#ChegadeFiuFiu, e \#VamosJuntas ${ }^{14}$. Segundo Pino (2017), os produtos culturais revelam que o fluxo cultural não deve ser examinado apenas pelo viés da influência ou da exploração unidirecional da mídia mainstream, pois permite "refluxos" ou reorganizações de sentidos não hegemônicos na produção, circulação e consumo desses artefatos que alimentam outras práticas e produtos culturais. Escola de Princesinhas exemplifica a reflexão do autor, pois abre uma fenda ou revela uma "falha" nas narrativas midiáticas hegemônicas das princesas clássicas e reverbera outras significações para o feminino imbricadas em disputas discursivas entre o global e o local, ainda que não seja plenamente original e desassociada das clássicas histórias de princesas por seu caráter de mockbuster.

\footnotetext{
14 Disponível em: https://revistaforum.com.br/noticias/em-campanha-no-twitter-mulheres-relatam-primeiroscasos-de-assedio-que-sofreram/; http://chegadefiufiu.com.br/; http://tabataamaral.com.br/vamosjuntas/. Acesso em: 27 mar. 2020.
} 


\section{Considerações Finais}

A partir da Análise Televisual da série animada Escola de Princesinhas, sugerimos que os conteúdos infantojuvenis que apresentam a figura da princesa no Brasil na contemporaneidade refletem a homogeneização da cultural global, porém, ao mesmo tempo, despontam resistências e mudanças sociais referentes ao posicionamento e ao empoderamento político de meninas e mulheres no país. Consideramos relevante ainda apreender no desenvolvimento deste estudo como as crianças atribuem sentidos às princesas, às relações entre meninos e meninas e aos ideais do feminismo na interação com o seriado na televisão e em outras mídias e plataformas. Partindo do pressuposto de que a criança é produtora de cultura, suas falas devem ser compreendidas como "revelação dos valores fundamentais de uma dada sociedade e do modo como esses valores se explicitam e se confrontam" (FERNANDES; OSWALD, 2005, p. 26).

Hoje, entretanto, novas produções sobre o feminino continuam a ser impulsionadas, por meio do desenvolvimento e uso de tecnologias digitais, da produção de imagens produzidas por computador e das novas dinâmicas de sociabilidade nas redes sociais. Chamamos aqui de "princesas cibernéticas" as cibermulheres que foram criadas como referenciais de beleza, elegância e fama, como Shudu (@shudu.gram), Miquela (@lilmiquela) e Imma (@Shugu.gram) ${ }^{15}$, com poder de pautar e influenciar significações do feminino na contemporaneidade. O número crescente dessas modelos virtuais indica uma retomada exacerbada do mito da beleza e um padrão de feminino inalcançável. Nesse sentido, este trabalho aponta ainda para a necessidade da contínua leitura crítica da mídia na formação das crianças, pois as produções de sentidos sobre as relações sociais, a desigualdade de gêneros, os modos de ser menina e suas próprias identidades também são construídas em suas interações com as animações que assistem na TV.

15 Disponível em: https://www.instagram.com/shudu.gram/?hl=pt-br; https: //www.instagram.com/lilmiquela/?hl=pt-br; https://www.instagram.com/imma.gram/?hl=pt-br. Acesso em: 24 mar. 2020. 


\section{REFERÊNCIAS}

BECKER, Beatriz. Mídia, Telejornalismo e Educação. Matrizes: Revista do Programa de Pós-Graduação em Ciências da Comunicação da Universidade de São Paulo, São Paulo: ECA/ USP, v. 10, n. 1, 2016

BECKER, Beatriz. Midia e Jornalismo como formas de conhecimento: uma metodologia para leitura crítica das narrativas jornalísticas audiovisuais. Matrizes: Revista do Programa de Pós-Graduação em Ciências da Comunicação da Universidade de São Paulo, São Paulo: ECA USP, v. 5, n. 2, p. 231-250, 2012

BARRETO, Paola Basso Menna. Princesas: produção de subjetividade feminina no imaginário de consumo. 2000. 208f. Dissertação (Mestrado em Educação) - Universidade Federal do Rio Grande do Sul, RS, 2000. Disponível em: https://docplayer.com.br/63343223-Princesas-producao-de-subjetividade-feminina-no-imaginario-de-consumo-paola-basso-menna-barreto-gomes.html. Acesso em: 27 mar. 2020

BOURDIEU, Pierre. A dominação masculina. Rio de Janeiro: Bertrand Brasil, 1998.

BREDER, Fernanda Cabanez. Feminismo e príncipes encantados: a representação feminina nos filmes de princesa da Disney. 2013. 74f. Trabalho de Conclusão de curso em Comunicação Social. Universidade Federal do Rio de Janeiro, RJ, 2013. Disponível em: https://pantheon.ufrj.br/ handle/11422/4022. Acesso em: 26 mar. 2020.

COUTINHO, Lúcia Loner. "É simplesmente diferente para meninas": amor e sexo em seriados de teen drama. ECO Pós. Revista do Programa de Pós-Gradauação em Comunicação e Cultura da Universidadee Federal do Rio de Janeiro, v. 20, n. 3, 2017. DOI: https://doi.org/10.29146/ eco-pos.v20i3.3787. Acesso em 21 mar. 2020

FARIA, Ana Lúcia Goulart de. Pequena infância, educação e gênero: subsídios para um estado da arte. Cad. Pagu [online], n.26, pp.279-287, 2006. DOI: https://doi.org/10.1590/S010483332006000100012. Acesso em: 26 mar. 2020.

FIEL, Arthur Felipe de O. A tela encantada: infância e conteúdo infantil na TV do Brasil. 2019. $208 f$. Dissertação (Mestrado) - Instituto de Artes e Comunicação Social. Universidade Federal Fluminense, Niterói, 2019

FISCHER, Rosa Maria Bueno. O Dispositivo pedagógico da mídia: modos de educar na (e pela) TV. Educação e Pesquisa, v. 28, n. 1, p. 151-162, 2002. DOI: https://doi.org/10.1590/S151797022002000100011. Acesso em: 20 mar. 2020.

FERNANDES, Adriana Hoffmann; OSWALD, Maria Luíza Bastos Magalhães. A recepção dos desenhos animados da TV e as relações entre a criança e o adulto: desencontros e encontros. Cadernos Cedes, v. 25, n. 65, 2005. DOI: https://doi.org/10.1590/S0101-32622005000100003. Acesso em 23 mar. 2020.

FUENZALIDA, Valerio. Política Pública: a televisão infantil na educação infantil. Comunicação \& Educação, v. 21 n. 2, p. 69-86 2016. DOl: https://doi.org/10.11606/issn.2316-9125.v21i2p69-86. Acesso em: 23 mar. 2019. 
GALVÃO, Walnice. A donzela guerreira. São Paulo: Editora SENAC, 1998.

HAINS, Rebecca C.; FORMAN-BRUNNEL, Miriam. Princess Cultures: Mediating Girls' Imaginations and Identities. 18 ed. Nova lorque: Peter Lang Inc., 2015. 313p.

HEATWOLE, Alexandra: Princess Generations and Once Upon a Time. Studies in the Humanities, v. 43. p. 1-19, 2016. Disponível em: https://law-journals-books.vlex.com/source/studies-humanities-3168/issue_nbr/\%2343\%231-2. Acesso em 27 mar. 2020.

HOLZBACH, Ariane Diniz; DORNELLES, Wagner. Definição pela exclusão: apontamentos iniciais sobre os limites conceituais dos programas infantis. Mídia e Cotidiano. Revista do Programa de Pós-Graduação em Mídia e Cotidiano da Universidade Federal Fluminense, v. 14, n. 1 , 2020. DOI: https://doi.org/10.22409/rmc.v14i1.38523. Acesso em: 24 mar. 2020.

HOLZBACH, Ariane Diniz. Para pequenos grandes espectadores: a produção televisiva brasileira direcionada a crianças pequenas a partir do caso da Galinha Pintadinha. E-Compós, v. 21, n. 2. DOI: https://doi.org/10.30962/ec.1390. Acesso em: 24 mar. 2020.

LAURETIS, Teresa. Alice Doesn't: Feminism, Semiotics, Cinema. Bloomington, Indiana: Indiana University Press, 1984. 220p.

LEAL, Tatiana. A ética da sororidade: sentimentos morais, gênero e mídia. Anais do XXVII Encontro anual da Compós. Belo Horizonte, MG. 05 a 08 de junho de 2018. Disponível em: http:// www.compos.org.br/data/arquivos_2018/trabalhos_arquivo_05RVT9I2R4XKIE2Q1VY9_27_ 6556_26_02_2018_13_50_29.pdf. Acesso em: 25 mar. 2020.

LEBLANC, Sarah. Taking Back the "P-Word": Princess Leia Feminism, an Autoethnography. The popular cultural studies jornal, v. 5, n. 1, p. 5-23, 2017. Disponível em: https://mpcaaca.org/ wp-content/uploads/2017/10/PCSJ_v5_12.pdf. Acesso em: 26 mar. 2020.

PINO, Camilo. Flows in Reflux: Video Brinquedo and the BRICS "Mockbuster" as a Glitch in Mediatic Hegemony. Television \& New Media, p.1-18, Mar. 2017. Disponível em: https://doi. org/10.1177/1527476417697272. Acesso em: 26 mar. 2020.

PRADO, Ana Lucia Penteado Brandão; MUNGIOLI, Maria Cristina. Educomunicação e Mediação Escolar: Um projeto educomunicativo para a relação Criança, Desenho Animado e Consumo. Comunicação \& Educação, v. 21, n. 2, p. 87-96, 2016. DOI: https://doi.org/10.11606/issn.23169125.v21i2p87-96. Acesso em: 22 mar. 2020.

SAMPAIO, Inês Sílvia Vitorino; CAVALCANTE, Andréa Pinheiro Paiva. Qualidade na programação infantil da TV Brasil. Florianópolis, SC: Editora Insular, 2012. 368p.

TOMAZ, Renata de Oliveira. Infância e mídia: breve revisão de um campo em disputa. Contracampo, Niterói, v. 35, n. 03, p. 272-294, 2016-2017. DOl: https://doi.org/10.22409/contracampo. v35i3.919. Acesso em: 22 mar. 2020.

Recebido em: 31/03/20

Aprovado em: 21/12/20 


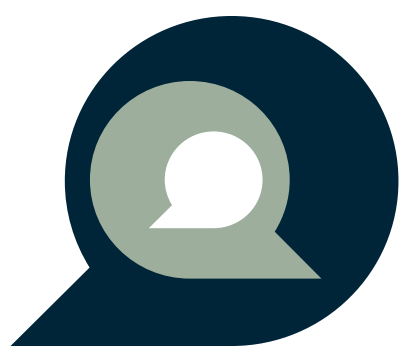

